\title{
Expression of urokinase-type plasminogen activator/ urokinase-type plasminogen activator receptor and maspin in oral squamous cell carcinoma: Association with mode of invasion and clinicopathological factors
}

\author{
KUNIO YOSHIZAWA ${ }^{1}$, SHINICHI NOZAKI ${ }^{2}$, HIROKO KITAHARA ${ }^{1}$, KOROKU KATO $^{1}$, \\ NATSUYO NOGUCHI ${ }^{1}$, SHUICHI KAWASHIRI ${ }^{1}$ and ETSUHIDE YAMAMOTO ${ }^{1}$ \\ ${ }^{1}$ Department of Oral and Maxillofacial Surgery, Kanazawa University Graduate School of Medical Science, \\ Kanazawa, Ishikawa; ${ }^{2}$ Oral and Maxillofacial Surgery, National Hospital Organization, \\ Kanazawa Medical Center, Kanazawa, Japan
}

Received June 20, 2011; Accepted July 22, 2011

DOI: 10.3892/or.2011.1419

\begin{abstract}
It is well documented that the binding of urokinasetype plasminogen activator (UPA) to its receptor (UPAR), which has been implicated in cancer invasion and metastasis, is regulated by several inhibitors such as maspin. In this study, we investigated the interrelationship between clinicopathologic findings and expression of UPA, uPAR and maspin in oral squamous cell carcinoma (OSCC) to elucidate the participation of maspin in the uPA/uPAR system in the malignant behavior of OSCC. Using immunohistochemical techniques to examine the expression levels of uPA, uPAR and maspin in 54 cases of OSCC, we also compared the clinicopathologic features of OSCC with the expression levels of each. Moreover, we examined the expression of UPA, uPAR and maspin in six cell lines derived from OSCC using reverse transcriptase-polymerase chain reaction (RT-PCR) and Western blotting. UPA and UPAR showed a positive correlation with the mode of cancer invasion; conversely maspin showed a negative correlation with the mode of invasion. Multivariate analysis revealed that only two factors (N-category and $\mathrm{uPA}^{+} / \mathrm{uPAR}^{+} /$maspin $^{-}$expression pattern) were significant and independent variables with rela-
\end{abstract}

Correspondence to: Dr Kunio Yoshizawa, Department of Oral and Maxillofacial Surgery, Kanazawa University Graduate School of Medical Science, 13-1 Takaramachi, Kanazawa, Ishikawa 920-8641, Japan

E-mail: yoshizawa@oral.m.kanazawa-u.ac.jp

Abbreviations: uPA, urokinase type plasminogen activator; UPAR, urokinase type plasminogen activator receptor; OSCC, oral squamous cell carcinoma; ECM, extracellular matrix; RT-PCR, reverse transcription-polymerase chain reaction; EMT, epithelial-tomesenchymal transition

Key words: oral squamous cell carcinoma, urokinase-type plasminogen activator, urokinase-type plasminogen activator receptor, maspin, invasion tive risks of 3.84 and 2.52 , respectively. In particular, tumors exhibiting an expression pattern of $\mathrm{uPA}^{+} / \mathrm{uPAR}^{+} / \mathrm{maspin}^{-}$were highly malignant and were associated with the worst survival rate (5-year overall survival rate, $29.4 \%$ ), while tumors with an expression pattern, $\mathrm{uPA}^{-} / \mathrm{uPAR}^{-} / \mathrm{Maspin}^{+}$, showed the most favorable survival rate (5-year overall survival rate, $77.8 \%$ ). In vitro, lower expression of maspin was also noted in the cell lines derived from grade 4D OSCC, which exhibited a stronger invasive potential than the cells lines derived from the other grades of OSCC, while UPA and UPAR demonstrated an expression trend opposite to maspin. These results indicate that UPA, uPAR and maspin expression patterns may be useful markers for evaluating the clinical course or prognosis of OSCC patients.

\section{Introduction}

In the absence of reliable molecular markers for use in early detection or as prognostic indicators, treatment failure remains difficult to predict. Thus, a more detailed analysis is a necessary prerequisite for the development of novel early detection and treatment strategies that can favorably impact the survival of OSCC patients. Therefore, markers are needed which are able to determine the necessity of elective clinical treatment in the absence of metastatic neck lymph nodes (N0) in oral SCCs. Several proteolytic enzyme systems, including plasminogen activators, matrix metalloproteinases (MMPs) and other enzymes, are considered to be intimately involved in the invasion and metastasis of tumor cells $(1,2)$. The serine protease urokinase-type of plasminogen activator (uPA) together with the $\mathrm{uPA}$ receptor (uPAR), which plays an essential role in the conversion of plasminogen to active plasmin, have been implicated in facilitating pericellular proteolysis and oncogenic signal transduction in cancer cells $(3,4)$. The proteolytic activity of UPAR-associated uPA is blocked by serine protease inhibitors such as maspin and PAI-1,2 (plasminogen activator inhibitor-1), leading to internalization of the trimeric complex, degradation of uPA and recycling of UPAR (5-9). Moreover, 
Table I. Yamamoto-Kohama classification.

\begin{aligned} & \hline Grade \multicolumn{1}{c}{ Histologic grading } \\ & \hline 1 Well-defined borderline \\ & 2 Cords, less marked borderline \\ & 3 Groups of cells, no distinct borderline \\ & $4 \mathrm{C}$ Diffuse invasion, cord-like type \\ & $4 \mathrm{D}$ Diffuse invasion, widespread type \\ & \hline\end{aligned}

surface-associated uPA is inhibited by recombinant maspin, suggesting that maspin may be a reliable marker for a more favorable prognosis. However, no studies exist concerning the possible association between the expression of uPA/uPARmaspin and the invasive potential of OSCC.

Invasion and metastasis are the most crucial characteristics of malignant tumors. Thus, the mode of invasion is used as a basis for histopathologic classification. The extent of invasion is determined based on the form of the borderline between the carcinoma of the epithelium and the stroma tissue of the host at the invasive front of OSCC, as described by Yamamoto et al (9) (Table I), and this classification is frequently used to predict progression and prognosis.

We, thus, immunohistochemically examined the expression of UPA, UPAR and maspin in vivo and compared their expression in cell lines derived from invasive OSCC in vitro to elucidate the relationship of the clinical findings of various clinicopathological parameters including mode of invasion and their expression levels.

\section{Materials and methods}

Specimens. Fifty-four biopsy specimens of primary OSCCs were obtained from patients undergoing surgical resection at the Department of Oral and Maxillofacial Surgery of Kanazawa University Hospital between 1988 and 2006. The patients ( 28 males and 26 females) ranged in age from 29 to 92 years (mean age, 63.5 years).

Staining methods. Immunohistochemical staining was performed by using by the labeled streptavidin-biotin (LSAB) method following deparaffinization and rehydration as described by Nozaki et al (10). The sections were reacted with the following primary antibodies: anti-maspin antibody (Lab Vision, Fremont, CA, USA) 300-fold diluted with PBS at $4^{\circ} \mathrm{C}$ overnight (11) and anti-uPA and uPAR (10) (no. 3689 and no. 3936; American Diagnostica Inc., USA) 200-fold diluted with PBS $4^{\circ} \mathrm{C}$ overnight. Regarding maspin, a section of normal oral epithelium previously identified as exhibiting strong staining was used as a positive control. With regard to UPA and uPAR, a routinely processed preparation of tumor tissue revealing strong expression of the tested antigens served as a positive control to ensure inter-assay consistency. Negative controls were treated with all reagents except the primary antibody.

Assessment of immunohistochemical staining of $u P A, u P A R$ and maspin proteins. Immunohistochemical reactivity for
UPA, UPAR and maspin was evaluated and classified into two groups; the expression of uPA, uPAR and maspin in tumor cells was evaluated as strong or weak-absent. A case was determined to be positive when a strong pattern of tumor cells could be detected in $>30 \%$ of the cancer tissue.

Cell culture and cell lines. Cell culture was performed as described previously by Nozaki et al (12). Cell lines were derived from OSCC with the following grades of invasiveness, according to the Yamamoto-Kohama criteria (9): HSC-4 and OSC-20 cells of grade 3 described as mildly invasive; OSC-19 and OTC-04 of grade 4C described as highly invasive; HOC313 and TSU of grade 4D described as most highly invasive.

$R N A$ extraction and reverse transcriptase-polymerase chain reaction $(R T-P C R)$. RT-PCR analysis was performed using the modifications of Conboy et al (13). RNA was extracted from cultured cells using an RNeasy kit (Qiagen, Hilden, Germany). Amplification was carried out using the following primers: uPA, 5'-CGG TGC ATG CAG TGT AAG AC-3' (forward) and 5'-AGC AGG AGA CAT CAA TGT GG-3' (reverse) (14); uPAR, 5'-AAG GAC TAC AGC GCT GAC AC-3' (forward) and 5'-AAC TCC TGC AGG CTT CAG TC-3' (reverse) (14); maspin, 5'-CAG GCA CAA CAA AAC TCG AA-3' (forward) and 5'-AAT CGG CAT CCA CAG AAA AG-3' (reverse) (15); and $\beta$-actin, 5'-GAA AAT CTG GCA CCA CAC CTT-3' (forward) and 5'-TTG AAG GTA GTT TCG TGG AT-3' (reverse) (14). PCR was carried out under the following conditions: $3 \mathrm{~min}$ at $94^{\circ} \mathrm{C}$, followed by cycles ( 24 for uPA, 24 for uPAR, 30 for maspin and 18 for $\beta$-actin) of 1 min at $94^{\circ} \mathrm{C}$, $1 \mathrm{~min}$ at $56^{\circ} \mathrm{C}$ and $1 \mathrm{~min}$ at $72^{\circ} \mathrm{C}$. All reactions were completed with a final incubation at $72^{\circ} \mathrm{C}$ for $10 \mathrm{~min}$. The lengths of the amplified fragments for uPA, uPAR, maspin and $\beta$-actin were 789, 792, 104 and 592 bp, respectively.

Western blot analysis. Samples $(25 \mu \mathrm{g})$ extracted from the whole cellular structure using M-PER Mammalian protein extraction reagent (Pierce, Rockford, IL, USA) were used for Western blotting as described previously by Yoshizawa et al (16). Antibodies were applied for $1 \mathrm{~h}$ : a 500-fold diluted polyclonal anti-rabbit antibody against maspin (BD Biosciences, San Jose, CA, USA), a 500-fold diluted monoclonal antimurine uPA (no. 3689; American Diagnostica Inc.) and 250-fold diluted monoclonal anti-murine uPAR (no. 3936; American Diagnostica Inc.), respectively and 5000-fold diluted polyclonal anti-mouse antibody $\beta$-actin (Sigma, St. Louis, MO, USA), respectively. The secondary antibody was 2000 -fold diluted horseradish peroxidase-conjugated anti-mouse IgG (Amersham, Buckinghamshire, UK) applied for $1 \mathrm{~h}$ to detect uPA, uPAR, maspin and $\beta$-actin, respectively.

Statistical analysis. Correlation between these factors was analyzed by the Mann-Whitney's U test, $\chi^{2}$ test or Fisher's exact probability test. Overall survival rates of the patients with positive and negative expression were calculated by the Kaplan-Meier method, and examined for statistical significance using the log-rank test. Cox proportional hazards regression analysis was performed by a stepwise procedure. Differences were considered significant at a P-value of $<0.05$. 
Table II. Clinicopathological parameters in relation to UPA, uPAR and maspin expression.

\begin{tabular}{|c|c|c|c|c|c|c|c|c|c|c|}
\hline \multirow[b]{2}{*}{ Variables } & \multirow[b]{2}{*}{$\mathrm{N}$} & \multicolumn{3}{|c|}{ uPA, no (\%) } & \multicolumn{3}{|c|}{ uPAR, no (\%) } & \multicolumn{3}{|c|}{ Maspin, no (\%) } \\
\hline & & Positive & Negative & P-value & Positive & Negative & P-value & Positive & Negative & P-value \\
\hline \multicolumn{11}{|l|}{ Age (years) } \\
\hline$\geq 65$ & 22 & $16(72.7)$ & $6(27.3)$ & 0.650 & 14 (63.6) & $8(36.4)$ & 0.880 & $12(54.5)$ & $10(45.5)$ & 0.190 \\
\hline$<65$ & 32 & $25 \quad(78.1)$ & $7(21.9)$ & & $21 \quad(65.6)$ & $11(34.4)$ & & $23 \quad(71.9)$ & $9(28.1)$ & \\
\hline \multicolumn{11}{|l|}{ Gender } \\
\hline Male & 28 & $24 \quad(85.7)$ & $4(14.3)$ & 0.080 & $19(67.9)$ & $9(32.1)$ & 0.630 & $16 \quad(57.1)$ & $12(42.9)$ & 0.220 \\
\hline Female & 26 & $17 \quad(65.4)$ & $9(34.6)$ & & $16(61.5)$ & $10(38.5)$ & & $19 \quad(73.1)$ & 7 (26.9) & \\
\hline \multicolumn{11}{|l|}{ Primary series } \\
\hline Tongue & 27 & $20 \quad(74.1)$ & $7(25.9)$ & 0.730 & $19(70.4)$ & $8(29.6)$ & 0.910 & $18 \quad(66.7)$ & $9(33.3)$ & 0.560 \\
\hline Buccal mucosa & 7 & $6 \quad(85.7)$ & $1(14.3)$ & & $3 \quad(42.9)$ & $4(57.1)$ & & $6 \quad(85.7)$ & $1(14.3)$ & \\
\hline Lower gingiva & 5 & $3(60.0)$ & $2(40.0)$ & & $3(60.0)$ & $2(40.0)$ & & $2(40.0)$ & $3(60.0)$ & \\
\hline Floor of mouth & 4 & $3(75.0)$ & $1(25.0)$ & & $2 \quad(50.0)$ & $2(50.0)$ & & $3(75.0)$ & $1(25.0)$ & \\
\hline Upper gingiva & 9 & $7 \quad(77.8)$ & $2(22.2)$ & & $7 \quad(77.8)$ & $2(22.2)$ & & $5 \quad(55.6)$ & $4(44.4)$ & \\
\hline Other & 2 & $2(100.0)$ & $\begin{array}{ll}0 & (0.0)\end{array}$ & & $2(100.0)$ & $0 \quad(0.0)$ & & $1 \quad(50.0)$ & $1(50.0)$ & \\
\hline \multicolumn{11}{|l|}{ T category } \\
\hline $\mathrm{T} 1$ & 15 & $8 \quad(53.3)$ & $7(46.7)$ & 0.070 & $6 \quad(40.0)$ & $9(60.0)$ & 0.060 & $11 \quad(73.3)$ & $4(26.7)$ & 0.310 \\
\hline $\mathrm{T} 2$ & 27 & $23 \quad(85.2)$ & $4(14.8)$ & & $20 \quad(74.1)$ & $7(25.9)$ & & $18(66.7)$ & $9(33.3)$ & \\
\hline $\mathrm{T} 3$ & 4 & $3(75.0)$ & $1(25.0)$ & & $3(75.0)$ & $1(25.0)$ & & $1 \quad(25.0)$ & $3(75.0)$ & \\
\hline $\mathrm{T} 4$ & 8 & $7 \quad(87.5)$ & $1(12.5)$ & & $6 \quad(75.0)$ & $2(25.0)$ & & $5 \quad(62.5)$ & $3(37.5)$ & \\
\hline \multicolumn{11}{|l|}{ N category } \\
\hline NO & 25 & $16(64.0)$ & $9(36.0)$ & 0.057 & $13(52.0)$ & $12(48.0)$ & 0.067 & $20 \quad(80.0)$ & $5(20.0)$ & 0.030 \\
\hline $\mathrm{N}+$ & 29 & $25 \quad(86.2)$ & $1(13.8)$ & & $22(75.9)$ & $7(24.1)$ & & $15 \quad(51.7)$ & $3(48.3)$ & \\
\hline \multicolumn{11}{|l|}{ Cell differentiation } \\
\hline Well & 32 & $23 \quad(71.9)$ & $9(28.1)$ & 0.266 & $17 \quad(53.1)$ & $15(46.9)$ & 0.046 & $21 \quad(65.6)$ & $11(34.4)$ & 0.690 \\
\hline Moderate & 12 & $8 \quad(66.7)$ & $4(33.4)$ & & $9 \quad(75.0)$ & $3(25.0)$ & & $9 \quad(75.0)$ & $3(25.0)$ & \\
\hline Poor & 10 & $10(100.0)$ & $\begin{array}{ll}0 & (0.0)\end{array}$ & & $9 \quad(90.0)$ & $1(10.0)$ & & $5 \quad(50.0)$ & $5(50.0)$ & \\
\hline \multicolumn{11}{|l|}{ Mode of invasion } \\
\hline 1 & 10 & $4 \quad(40.0)$ & $6(60.0)$ & $<0.001$ & $1 \quad(10.0)$ & $9(90.0)$ & $<0.001$ & $9 \quad(90.0)$ & $1(10.0)$ & $<0.001$ \\
\hline 2 & 8 & $3 \quad(37.5)$ & $5(62.5)$ & & $2 \quad(25.0)$ & $6(75.0)$ & & $8(100.0)$ & $0 \quad(0.0)$ & \\
\hline 3 & 11 & $10(90.9)$ & $1 \quad(9.1)$ & & $7 \quad(63.6)$ & $4(36.4)$ & & $11(100.0)$ & $0 \quad(0.0)$ & \\
\hline $4 \mathrm{C}$ & 15 & 14 (93.3) & $(6.7)$ & & $15(100.0)$ & $0 \quad(0.0)$ & & $5 \quad(33.3)$ & $10(66.7)$ & \\
\hline $4 \mathrm{D}$ & 10 & $10(100.0)$ & $(0.0)$ & & $10(100.0)$ & $0 \quad(0.0)$ & & $2(20.0)$ & $8(80.0)$ & \\
\hline
\end{tabular}

\section{Results}

Immunohistochemistry and evaluation. The relationship between the clinicopathological parameters and the expression of UPA, uPAR and maspin is summarized in Table II. The positive rate of UPA, UPAR and maspin expression was $75.9 \%$ $(41 / 54), 64.8 \%(35 / 54)$ and $64.8 \%(35 / 54)$, respectively. The staining pattern of uPA was more prominent where the edge of the cancer nest was expanding. The adjacent stromal cells were also stained in a few cases. The staining pattern of uPAR was very similar to that of UPA. UPA and UPAR were observed to be almost co-localized $(\mathrm{P}<0.001)$. Cases with maspin-positive immunostaining (35/54) were noted and the pattern of expression in the tumor cells was nuclear $(51.4 \% 18 / 35)$, cytoplasmic (5.7\% 2/35) and nuclear-cytoplasmic (42.9\% 15/35). The nuclear pattern was associated with a more favorable 5-year survival rate $(72.2 \%)$ than cytoplasmic $(50 \%)$ and nuclear-cytoplasmic $(59.3 \%)$ pattern, although a significant difference was not achieved (date not shown). Significant differences were noted between UPAR expression and the degree of cell differentiation, indicating that the frequency of cases with positive UPAR expression increased with decreasing degree of cell differentiation $(\mathrm{P}<0.05)$. The frequency of cases with positive maspin expression was higher in the cases with positive lymph node metastasis $(\mathrm{P}<0.05)$. Moreover, uPA, uPAR and maspin expression was found to correlate with mode of invasion $(\mathrm{P}<0.001)$. The frequency of cases with UPA and UPAR positive expression increased with the aggressiveness of invasion. In contrast, the frequency of cases with maspin expression decreased in relation to the aggressiveness of the invasion (Fig. 1).

The 5-year overall survival rate was $51.4 \%$. The respective 5-year overall survival rates of cases with uPA, uPAR 

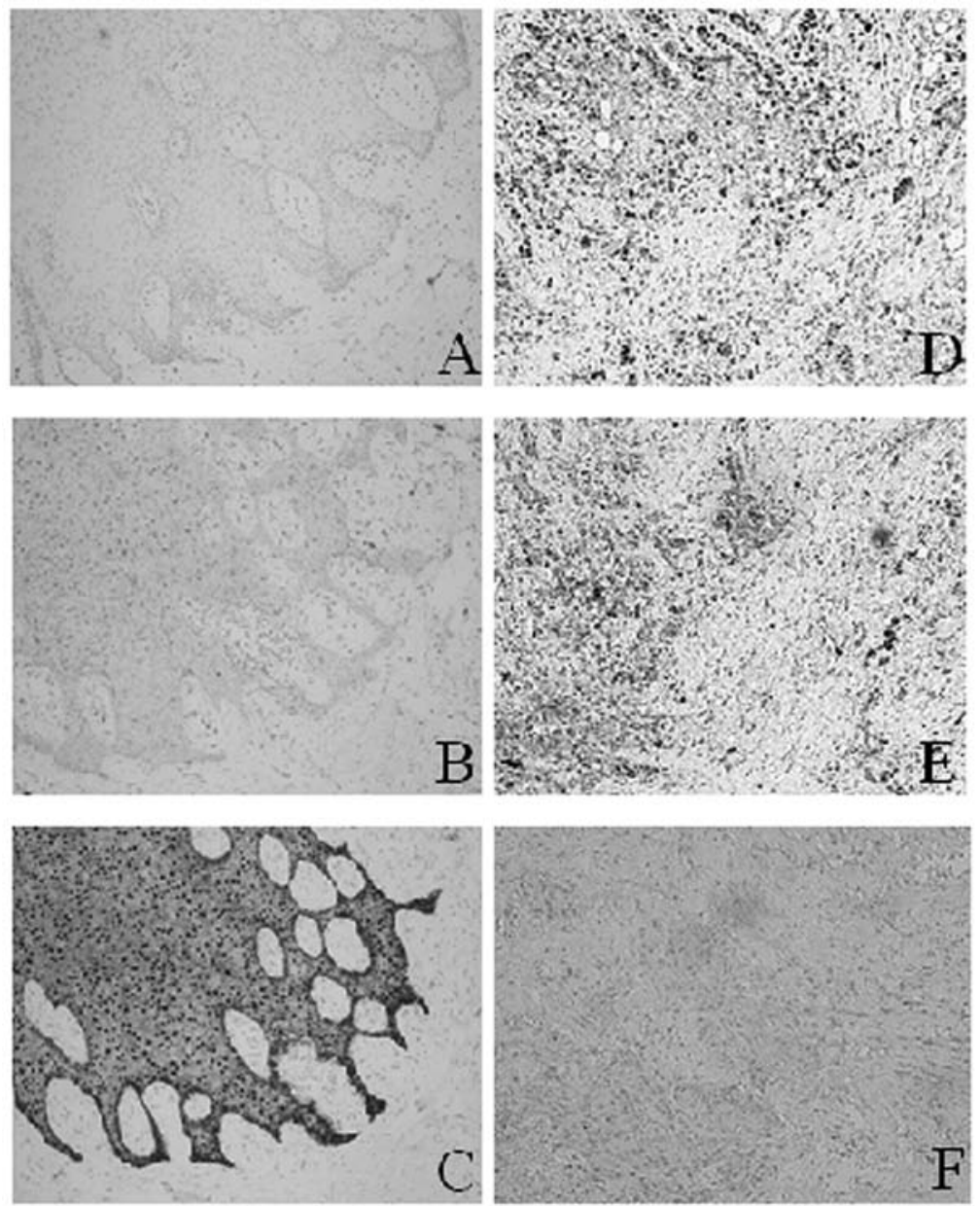

Figure 1. Immunohistochemical reactivity for UPA, uPAR and maspin. (A) uPA in grade 2, (B) uPAR in grade 2, (C) maspin in grade 2, (D) uPA in grade 4D, (E) uPAR in grade 4D, $(F)$ maspin in grade 4D OSCC (x100). A few stromal cells are positive for uPA, uPAR and maspin.

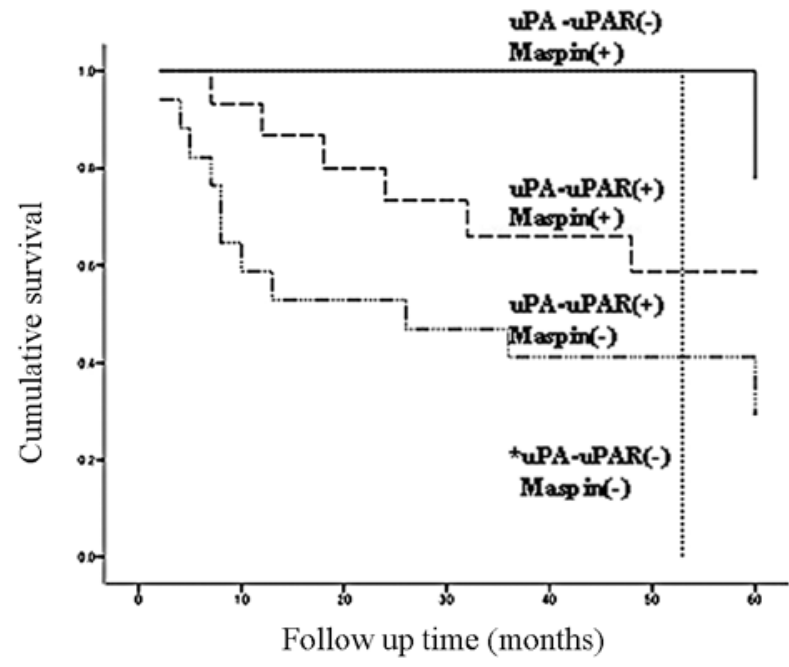

Figure 2. Kaplan-Meier survival estimates for 5-year overall survival in the cases with differing patterns of uPA, uPA and maspin expression. "uPA(-)/ uPAR(-)/Maspin(-) expression was noted in only one case; censored at 53 months.

and maspin positive expression/negative expression were 48.2/61.5\%, 42.0/68.4\% and 65.1/26.3\%; however, only uPA expression showed no significant difference in the log-rank test $(\mathrm{P}=0.22)$. Moreover, we divided the expression patterns into the following 5 groups: group $1, \mathrm{uPA}^{+} / \mathrm{uPAR}^{+} / \mathrm{maspin}^{+}$ (15/54); group 2, $\mathrm{uPA}^{+} / \mathrm{uPAR}^{+} / \mathrm{maspin}^{-}$(17/54); group 3, $\mathrm{uPA}^{-} /$ uPAR $/$ maspin $^{+}$(9/54); group 4, uPA-/uPAR $/$maspin $^{-}(1 / 54)$; group 5, uPA and uPAR were not related (12/52), respectively. The 5-year survival rates of groups 1-5 were 58.7, 29.4, 77.8, 0 (one case) and $58.3 \%$ The expression pattern of $\mathrm{uPA}^{+} / \mathrm{uPAR}^{+} /$ maspin was associated with the worst survival rate and showed a significant difference compared with the other expression patterns $(\mathrm{P}<0.01)$. In contrast, the expression pattern of $\mathrm{uPA} /$ $\mathrm{uPAR}^{-} / \mathrm{maspin}^{+}$was associated with the highest survival rate and showed a significant difference compared with $\mathrm{uPA}^{+} /$ $\mathrm{uPAR}^{+} /$maspin $^{-}(\mathrm{P}<0.05)$ (Fig. 2).

Table III summarizes the univariate and multivariate analyses of the clinicopathological and immunohistochemical variables, respectively, with respect to overall survival. Multivariate analysis revealed that the N-category and $\mathrm{uPA}^{+} /$ $\mathrm{uPAR}^{+} /$maspin $^{-}$expression pattern were significant and independent variables with relative risks of 3.84 and 2.52, respectively.

Analysis of uPA, uPAR and maspin mRNA levels in OSCC cell lines by RT-PCR. Expression of maspin was significantly lower in the HOC313 and TSU cell lines (grade 4D) when compared with the other cell lines. In contrast, expression of 
Table III. Univariate and multivariate analyses for clinical parameters, uPA, uPAR and maspin expression in relation to overall survival of 54 patients with oral squamous cell carcinoma.

\begin{tabular}{|c|c|c|c|c|c|c|c|}
\hline \multirow[t]{2}{*}{ Variables } & \multirow[t]{2}{*}{ Clinical groups } & \multirow{2}{*}{$\begin{array}{c}\text { Survivors } \\
\mathrm{n}=28\end{array}$} & \multirow{2}{*}{$\begin{array}{c}\text { Non-survivors } \\
n=26\end{array}$} & \multicolumn{2}{|c|}{ Log-rank } & \multirow{2}{*}{$\frac{\text { Cox regression }}{\text { P-value }}$} & \multirow[t]{2}{*}{ Risk ratio (95\% CI) } \\
\hline & & & & $\chi^{2}$ & P-value & & \\
\hline T category & $\mathrm{T} 3,4 / \mathrm{T} 1,2$ & $3 / 25$ & $9 / 17$ & 8.811 & 0.003 & & \\
\hline $\mathrm{N}$ category & N+/N0 & $4 / 24$ & $14 / 12$ & 15.25 & 0 & 0.001 & $3.84(1.750-8.426)$ \\
\hline Cell differentiation & Mod-poor/Well & $8 / 20$ & $14 / 12$ & 5.085 & 0.024 & & \\
\hline Mode of invasion & 3-4D/1-2 & $15 / 13$ & $21 / 5$ & 6.676 & 0.010 & & \\
\hline uPA & +/- & $20 / 8$ & $21 / 5$ & 1.471 & 0.225 & & \\
\hline uPAR & $+/-$ & $15 / 13$ & $20 / 6$ & 4.695 & 0.030 & & \\
\hline Maspin & $+/-$ & $23 / 5$ & $12 / 14$ & 10.01 & 0.020 & 0.07 & $0.342(0.157-0.746)$ \\
\hline $\mathrm{uPA}^{+} / \mathrm{uPAR}^{+} / \mathrm{maspin}^{+}$ & $+/-$ & $9 / 19$ & $6 / 20$ & 0.271 & 0.602 & & \\
\hline $\mathrm{uPA}^{+} / \mathrm{uPAR}^{+} / \mathrm{maspin}^{-}$ & $+/-$ & $5 / 23$ & $12 / 14$ & 7.46 & 0.006 & 0.02 & $2.52(1.159-5.483)$ \\
\hline $\mathrm{uPA}^{-} / \mathrm{uPAR}^{-} / \mathrm{maspin}^{+}$ & $+/-$ & $7 / 21$ & $2 / 24$ & 3.344 & 0.067 & & \\
\hline
\end{tabular}

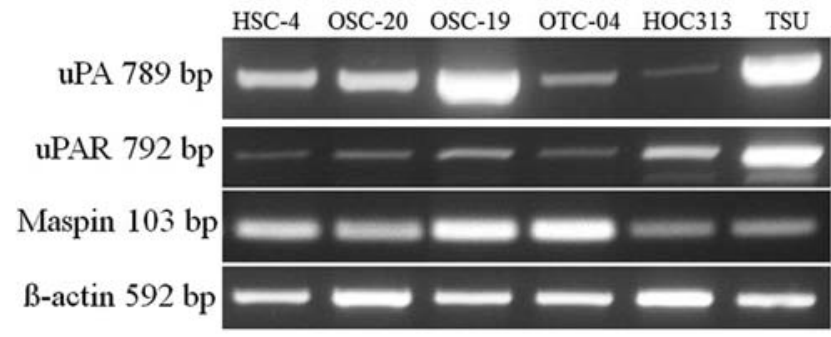

Figure 3. Expression of uPA, uPAR and maspin mRNA.

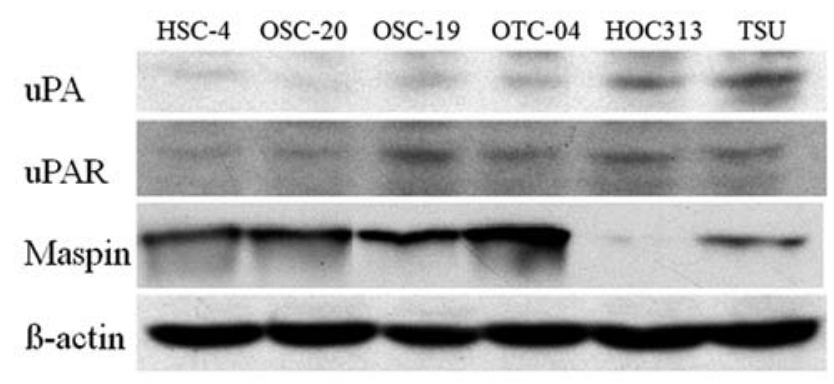

Figure 4. Expression of uPA, uPAR and maspin protein.

uPAR was comparatively higher in the grade 4D cell lines than in the others. With regard to uPA, its expression was higher in OSC-19 and TSU than in the other cell lines, and had no correlation with mode of invasion (Fig. 3).

Analysis of maspin $u P A, u P A R$ and maspin protein levels in the OSCC cell lines by Western blotting. Expression of maspin was significantly lower in the HOC 313 and TSU cell lines (grade 4D) compared with the other cell lines. uPA and UPAR expression levels were weaker in grade 3 cell lines compared with the other cell lines (Fig. 4).

\section{Discussion}

This study showed that as the invasiveness of OSCC increased, the expression of uPA/uPAR, which infiltrates the extracellular matrix, became stronger, while maspin which suppresses the function of uPA/uPAR became weaker.

Recently, many researchers have reported that the mechanism by which maspin suppresses tumors is through the differences in its subcellular localization rather than through differences in expression (positive and negative) (17-19). Xia et al (20) and Yasumatsu et al (21) reported that decreased maspin expression in OSCC is associated with an unfavorable clinical outcome due to invasion and lymph node metastasis, which is supported by the results of this study. In contrast, Marioni et al (18) and Sood et al (19) demonstrated that cytoplasmic subcellular localization of maspin in laryngeal and ovarian carcinoma was associated with a poor patient prognosis, whereas nuclear maspin localization was indicative of a less aggressive lesion.

Although it is unclear why higher invasion and poorer prognosis are commonly observed features in cases with both negative and cytoplasmic localization of maspin expression compared with cases of positive and nuclear localization of maspin expression, the possibility exists that in the absence of a nuclear localization signal, maspin, which is normally expressed in the nucleus, crosses the nuclear membrane by passive diffusion to the cytoplasm resulting in a decrease in its function as a tumor suppressor (7). However, the significance and mechanism of subcellular localization of maspin are still unclear.

Moreover, grade 4D OSCC tumors in particular, show a heterogeneity that differs from those of other grades. For example, the epithelial-mesenchymal transition (EMT) characteristic is present as a spindal shape, and the level of E-cadherin is low (22). Ets-1 is known to belong to a family of transcription factors implicated in the regulation of several matrix-degrading proteinases, including maspin and urokinase-type PA via the Ets-1 binding sites in the promoters of these genes $(23,24)$. Moreover, Ets-1 functions as an effector 
for EMT, and it enhances the malignancy of SCC cells though the regulation of proteolytic enzymes in the course of EMT (25). Thus, grade 4D tumors may become aggressively invasive due to the role of EMT, which is related to proteolytic enzymes, including maspin and uPA and is correlated with invasion by regulating the expression of Ets-1.

In conclusion, maspin, uPA and UPAR may be useful markers with which to identify the potential for progression of OSCC. Cases with $\mathrm{uPA}^{+} / \mathrm{uPAR}^{+} /$maspin expression, in particular, should be considered to have a higher risk of a poor prognosis of OSCC with the potential for severe invasiveness and a high risk of cervical lymph node metastasis. This implies the need for elective treatment in clinical cases of N0 with $\mathrm{uPA}^{+} / \mathrm{uPAR}^{+} /$maspin $^{-}$expression. It is necessary to clarify the underlying mechanisms between maspin and uPA/uPAR expression and the progression of OSCC for clinical application to become possible.

\section{Acknowledgements}

This study was supported by a Grant-in-Aid for Scientific Research (no. 21791982) from the Ministry of Education, Science, Sports and Culture of Japan.

\section{References}

1. Dass K, Ahmad A, Azmi AS, Sarkar SH and Sarkar FH: Evolving role of uPA/uPAR system in human cancers. Curr Cancer Ther Rev 34: 122-136, 2008.

2. Shi Z and Stack MS: Uninary-type plasminogen activator (uPA) and its receptor (UPAR) in squamous cell carcinoma of the oral cavity. Biochem J 407: 153-159, 2007.

3. Nowicki TS, Kummer NT, Iacob C, et al: Inhibition of uPAR and UPA reduces invasion in papillary thyroid carcinoma cells. Laryngoscope 120: 1383-1390, 2010.

4. Izuhara K, Ohta S, Kanaji S, Shiraishi H and Arima K: Recent progress in understanding the diversity of the human ov-serpin/ clade B serpin family. Cell Mol Life Sci 65: 2541-2553, 2008.

5. Amir S, Margaryan NV, Odero-Marah V, Khalkhali-Elis Z and Hendrix MJ: Maspin regulates hypoxia-mediated stimulation of uPA/uPAR complex in invasive breast cancer cells. Cancer Biol Ther 4: 400-406, 2005.

6. Bailey CM, Khalkhale-Ellis Z, Seftor EA and Hendrix MJ: Biological functions of maspin. J Cell Physiol 209: 617-624, 2006

7. Khalkhali-Ellis Z: Maspin: the new frontier. Clin Cancer Res 12: 7279-7283, 2006.

8. Biliran HJr and Sheng S: Pleiotrophic inhibition of pericellular urokinase-type plasminogen activator system by endogenous tumor suppressive maspin. Cancer Res 61: 8676-8682, 2001.

9. Yamamoto E, Miyakawa A and Kohama G: Mode of invasion and lymph node metastasis in squamous cell carcinoma of the oral cavity. Head Neck Surg 6: 938-947, 1984.
10. Nozaki S, Endo Y, Kawashiri S, et al: Immunohistochemical localization of a urokinase-type plasminogen activator system in squamous cell carcinoma of the oral cavity: association with mode of invasion and lymph node metastasis. Oral Oncol 34: 58-62, 1998.

11. Kumamoto $H$ and Ooya $K$ : Immunohistochemical detection of uPA, uPAR, PAI-1, and maspin in ameloblastic tumors. J Oral Pathol Med 36: 488-494, 2007.

12. Nozaki S, Endo Y, Nakahara $\mathrm{H}$, et al: Inhibition of invasion and metastasis in oral cancer by targeting urokinase-type plasminogen activator. Oral Oncol 41: 971-977, 2005.

13. Conboy JG, Chan J, Mohandas N and Kan YW: Multiple protein 4.1 isoforms produced by alternative splicing in human erythroid cells. Proc Natl Acad Sci USA 85: 9062-9065, 1988.

14. Noguchi-Takino M, Endo Y, Yonemura Y and Sasaki T: Relationship between expression of plasminogen activator system and metastatic ability in human cancers. Int $\mathrm{J}$ Oncol 8: 97-105, 1996.

15. Gery S, Tanosaki S, Bose S, Bose N, Vadgama J and Koeffler HP: Down-regulation and growth inhibitory role of C/EBPalpha in breast cancer. Clin Cancer Res 11: 3184-3190, 2005.

16. Yoshizawa K, Nozaki S, Okamune A, et al: Loss of maspin is negative factor for invasion and metastasis in oral squamous cell carcinoma. J Oral Pathol Med 38: 535-539, 2009.

17. Lonardo F, Li X, Siddiq F, et al: Maspin nuclear localization is linked to favorable morphological features in pulmonary adenocarcinoma. Lung Cancer 51: 31-39, 2006.

18. Marioni G, Gaio E, Giacomelli L, et al: Maspin subcellular localization and expression in oral cavity squamous cell carcinoma. Eur Arch Otorhinolaryngol 265: S97-S107, 2008.

19. Sood AK, Fletcher MS, Gruman LM, et al: The paradoxical expression of maspin in ovarian carcinoma. Clin Cancer Res 8: 2924-2932, 2002.

20. Xia W, Lau YK, Hu MC, et al: High tumoral maspin expression is associated with improved survival of patients with oral squamous cell carcinoma. Oncogene 19: 2398-2403, 2000.

21. Yasumatsu R, Nakashima T, Hirakawa N, Kumamoto Y, Kuratomi Y, Tomita K and Komiyama S: Maspin expression in stage I and II oral tongue squamous cell carcinoma. Head Neck 23: 962-966, 2001.

22. Taki M, Verschueren K, Yokoyama K, Nagayama M and Kamata N: Involvement of Ets-1 transcription factor in inducing matrix metalloproteinase- 2 expression by epithelial-mesenchymal transition in human squamous carcinoma cells. Int J Oncol 28: 487-496, 2006

23. Zhang M, Maass N, Magit D and Sager R: Transactivation through Ets and Ap1 transcription sites determines the expression of the tumor-suppressing gene maspin. Cell Growth Differ 8: 179-186, 1997.

24. Gilles C, Polette M, Birembaut P, Brünner N and Thompson EW: Expression of c-ets-1 mRNA is associated with an invasive, EMT-derived phenotype in breast carcinoma cell lines. Clin Exp Metastasis 15: 519-526, 1997.

25. Wernert N, Gilles F, Fafeur V, et al: Stromal expression of c-Ets1 transcription factor correlates with tumor invasion. Cancer Res 54: 5682-5688, 1994. 